\title{
Characteristics of increasing displacement efficiency by surface-active polymer flooding for enhancing oil recovery
}

\author{
Qiannan Yu ${ }^{1}$ - Yikun $\mathrm{Liu}^{2} \cdot$ Shuang Liang ${ }^{2} \cdot{\text { Shuai } \operatorname{Tan}^{3} \cdot \text { Chenghan Chen }}^{4} \cdot$ Zhi Sun $^{5} \cdot$ Yang Yu $^{5}$
}

Received: 8 July 2019 / Accepted: 15 February 2021 / Published online: 7 March 2021

(c) The Author(s) 2021

\begin{abstract}
Surface-active polymer is a novel multifunctional active polymer applied for enhancing oil recovery which has both viscosityincreasing ability and surface activity. Experiments were carried out to indicate basic physicochemical properties of surfaceactive polymer and to study on differences of properties between surface-active polymer and other chemical flooding agents, and characteristics of increasing displacement efficiency by surface-active polymer flooding have been tested. Experimental results show that the molecular aggregation conformation, viscosity performance and flow capacity of surface-active polymer were significantly different from those of other chemical flooding agents. Positive effects of viscosity and viscoelastic properties and improvements in interfacial chemical properties are basic characteristics of increasing displacement efficiency by surface-active polymer flooding which are basic principles of surface-active polymer flooding for enhancing oil recovery.
\end{abstract}

Keywords Surface-active polymer · Displacement efficiency $\cdot$ Enhanced oil recovery $\cdot$ Viscosity and viscoelastic property · Interfacial chemical property

\section{Introduction}

Chemical flooding has become common enhancing oil recovery technique for development of mature oilfield, which has achieved certain development effects. At present, there are many kinds of chemical agents used for chemical

Yikun Liu

liuyikun111@126.com

Shuang Liang

liangshuang21@163.com

Qiannan Yu

canaan184@163.com

1 College of Mechanical and Electrical Engineering, Guangdong University of Petrochemical Technology, Maoming 525000, China

2 School of Petroleum Engineering, Northeast Petroleum University, Daqing 163318, China

3 School of Chemical Engineering, Sichuan University, Chengdu 610065, China

4 Biomass Energy Technology Research Center, Biogas Institute of Ministry of Agriculture and Rural Affairs, Chengdu 610041, China

5 PetroChina, Daqing Oil Field Co. Ltd., Daqing 163002, China flooding. Chemical agents with single function still have different degrees of drawbacks. In a lot of previous studies, the experimental study of chemical flooding focused on the evaluation of performance and application, and the properties and flooding effects of different chemical agents have been extensively tested. The application of single functional chemical agents is limited (Gurgel et al. 2008; Liao et al. 2017). Polymer flooding is used to improve the viscosity of injected fluid and improve mobility ratio, while the viscoelasticity of polymer is beneficial to improve the oil drive efficiency (Stavland et al. 2010). However, the interfacial tension between the injection fluid and crude oil is high, and polymers basically have no capacity of solubility and emulsification, polymer flooding is limited, as oil recovery in yield is generally increased by only $7-13 \%$. Binary and ternary chemical compound flooding achieves ultra-low interface pressure of oil and water while maintaining the viscosity of the injected fluid, further increasing oil recovery (Xia et al. 2008; Yu et al. 2018). The synergy effect of different chemical agents with different functions in compound system is difficult to play (Yu et al. 2012; Sun et al. 2018), and oil recovery in yield increased by binary and ternary chemical compound flooding is about $20 \%$.

Surface-active polymer is a novel active multifunctional polymer. Surface-active polymer is formed by grafting and 
copolymerization of multiple functional groups on the polymer molecular chain, and has function and properties both of polymer and surfactant (Shi 2008; Liu et al. 2012). The research of surface-active polymer is still in the initial stage, basic mechanism of enhancing oil recovery by surface-active polymer flooding is to be further studied.

\section{Experimental section}

Experiments were carried out to test the properties of surface-active polymer and to analyze the differences of properties between surface-active polymer and other chemical flooding agents, and further to study on characteristics of increasing displacement efficiency by surfaceactive polymer flooding for enhancing oil recovery.

\section{Experimental chemical agents}

Experiments on differences of properties between surfaceactive polymer and other chemical flooding agents adopted surface-active polymer, partial hydrolyzed polyacrylamide (HPAM) and binary compound system of partial hydrolyzed polyacrylamide and heavy alkyl benzene sulfonate surfactant (HPAM/HABS) as test chemical agents. Surface-active polymer was developed by Northeast Petroleum University and Petrochina Daqing Oil Field Co. Ltd. The molecular weight of surface-active polymer is $1250 \times 10^{4}$, molecular weight of HPAM is $1300 \times 10^{4}$, and mass fraction of HABS in binary compound system is $0.2 \%$. The test oil is proportional mixture of degassed crude and kerosene, and the viscosity of test oil is $9.8 \mathrm{mPa} \cdot \mathrm{s}$ at $45^{\circ} \mathrm{C}$. The mineralization of test water is $3700 \mathrm{mg} / \mathrm{L}$, and the composition and content of mineral ions in test water are same as injection water in typical mature oilfield. The specifications of chemical agents and other experimental materials are the same as these of experiments on properties and characteristics of surface-active polymer for experiments on viscosity-increasing performance and viscoelastic properties of surface-active polymer.

\section{Experimental instruments}

Experimental instruments include PerkinElmer FI-IR Spectrometer, HITACHI S-3400 N scanning electron microscope, BROOKHAVEN BI-200SM dynamic laser scattering apparatus, BROOKFIELD DV-II + PRO Brookfield viscometer, HJ-6 magnetic stirrer, thermostat, electronic balance, beaker and test tube. Experimental apparatuses include constant-flux pump, pressure sensors, core grippers, and intermediate containers. TX550A spinning drop interfacial tension meter and OCA20 optical interfacial contact angle meter are applied to experiments on interfacial tension and wettability.

\section{Experimental procedures}

\section{Experiments on basic physicochemical properties of surface-active polymer}

Basic physicochemical properties included density, solid content, hydrolysis degree, viscosity, water insoluble content, dissolution rate and particle size of surface-active polymer were tested by physicochemical experiments.

Surface-active polymer powder was ground to pieces with aching, the grinding tablets are made of potassium bromide to powder, potassium bromide and chemical agents are made into pressure sheets, and the tablets are placed in infrared chromatography for test. Infrared spectrum of surface-active polymer was draw to characterize molecular structure and characteristic functional group of surface-active polymer according to infrared absorption characteristics frequency of functional groups.

\section{Experiments on differences of properties between surface-active polymer and other chemical flooding agents}

Conformation of molecular aggregation, performance of viscosity and capability of transmission and flow were tested to indicate differences of properties between surface-active polymer and other chemical flooding agents.

Solution of surface-active polymer was dripped in microscope stainless steel concave sampling tank, inject liquid nitrogen vacuuming to remove water from solution and get dry samples, and scanning electron microscope was used to analyze conformation of molecular aggregation.

Diluted after preparation of mother solution at normal temperature, stirring time should be $>2 \mathrm{~h}$ to fully hydrate and stretch the molecular chain of chemical agents. Dust was filtered with nuclear micropore membrane, and sample bottles were cleaned with ultrasonic cleaner for not less than $5 \mathrm{~min}$. Heated water bath were adjusted to desired temperature, and the sample bottle is placed in the scattering pool for testing. Turn on the laser and adjust the photod ration so that the scattered light strength measured by the relevant device is within the appropriate range. Each sample has been tested for $2 \mathrm{~min}$, and the detection laser wavelength and dynamic light scattering angle are adjusted to the appropriate value. Molecular coil dimension $\left(D_{h}\right)$ curves of chemical agents were drawn to analyze conformation of molecular aggregation. 
Fig. 1 Schematic diagram of experimental model for transmission migration ability

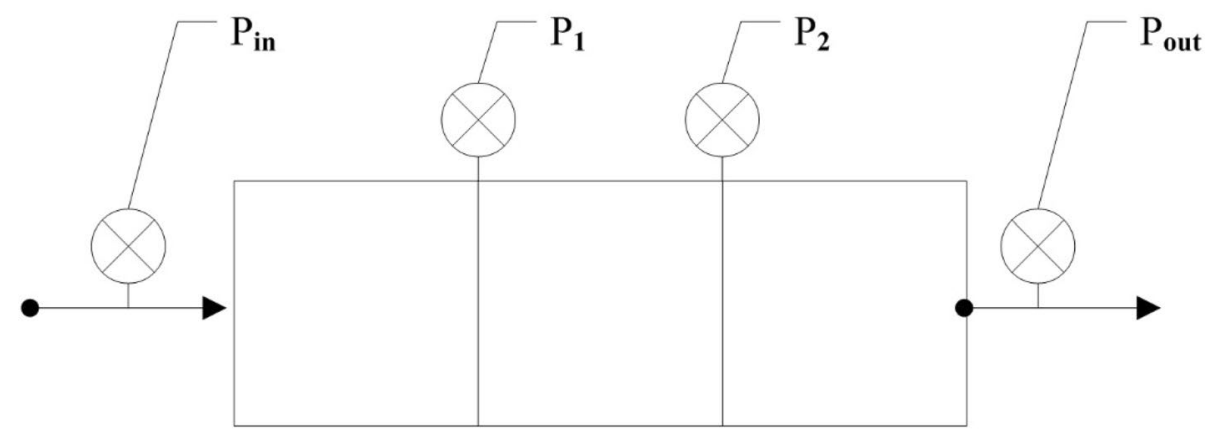

Displacement experiments were carried out using artificial cores cemented with epoxy resin adhesive and quartz sand, and artificial cores with same permeability and solution of surface-active polymer were used to ensure the comparability and repeatability of the experiment. HPAM and HPAM/HABS with same concentration, experimental model and pressure measurement points were set as Fig. 1. Pressure measuring points were set at trisection points, injection end and production end. Solution of different chemical agents was injected from the injection end of core and produced from the other end. The capacity of transmission was evaluated by comparing the pressure differences in different parts of cores after chemical flooding.

\section{Experiments on characteristics of increasing displacement efficiency by surface-active polymer flooding.}

Viscosity and viscoelastic properties and interfacial chemical properties were tested to indicate characteristics of increasing displacement efficiency by surface-active polymer flooding.

The mother solution of surface-active polymer was made with clear water, the concentration of the experimental conditions was determined by dilution of test water, the fluidity of the solution was determined at $45^{\circ} \mathrm{C}$. Viscosity and viscoelastic properties of surfaceactive polymer were tested with of $180 \mathrm{~s}$ and shear rate of $0.045-2000 \mathrm{~s}^{-1}$, and interfacial tension of surface-active polymer with different concentrations was tested.

The emulsion was prepared proportionally with crude oil and surface-active polymer solution, the interface of oil and water was observed after a period of static time, and the ability of emulsifying crude oil was analyzed by dewatering rate.

Contact angle of end face of cores is measured after the cores were vacuumed. Cores were saturated with salt water and placed in a thermostat for at least $3 \mathrm{~h}$, cores after surface-active polymer flooding were placed in

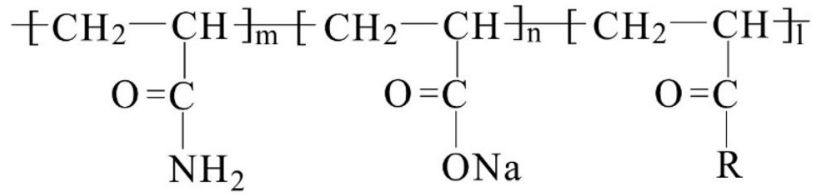

Fig. 2 Molecular structure diagram of surface-active polymer

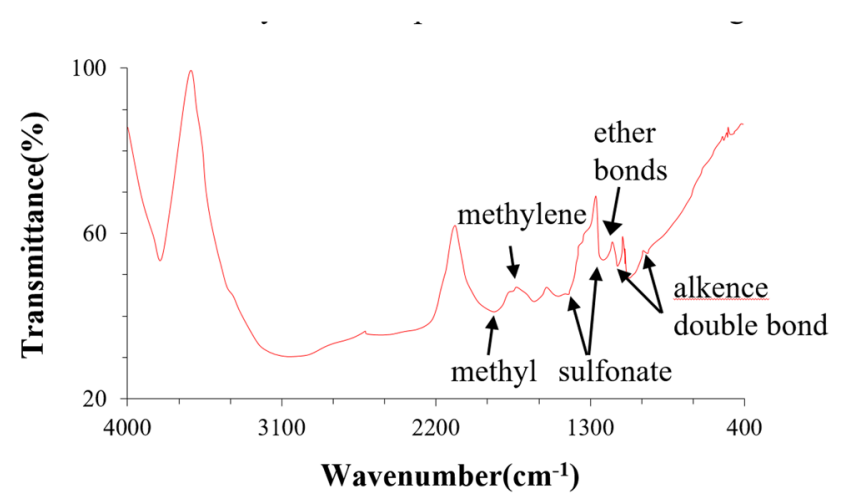

Fig. 3 Infrared spectrum of surface-active polymer

thermostat until dried, and then contact angle of end face of cores is measured to indicate the interfacial chemical properties by surface-active polymer.

\section{Results and discussion}

\section{Basic physicochemical properties of surface-active polymer}

Polymer-surfactant is formed by grafting and copolymerization of multiple functional groups using the alkyl chain of acrylamide and sodium acrylate as skeleton. The introduced functional groups are dendritic hydrophobic monomer, alkyl sulfonate surfactant unit, active sulfides

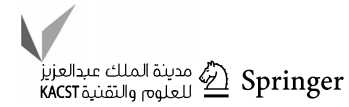


Table 1 Physicochemical properties of surface-active polymer

\begin{tabular}{lllllll}
\hline Density (g/mL) & Solid content (\%) & $\begin{array}{l}\text { Hydrolysis degree } \\
\text { mol) }\end{array}$ & Viscosity (mPa s) & $\begin{array}{l}\text { Water-soluble } \\
\text { content (Wt\%) }\end{array}$ & Dissolutionate (h) & $\begin{array}{r}\text { Particle size } \\
\leq 0.2(\mathrm{~mm})\end{array}$ \\
\hline 0.653 & 88.83 & 21.5 & $\geq 42.3$ & 0.07 & $\leq 1.0$ & 2.7 \\
\hline
\end{tabular}

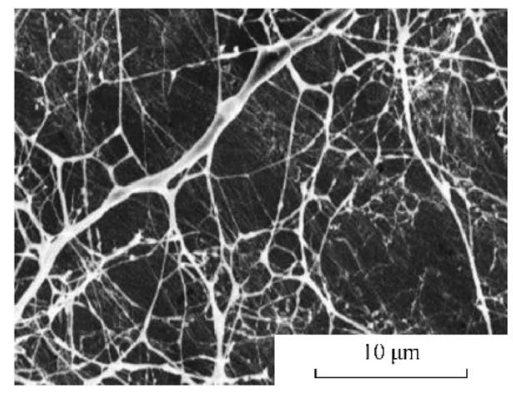

(a) HPAM

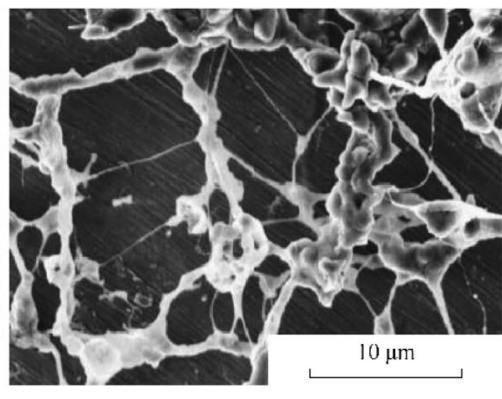

(b) HPAM/HABS

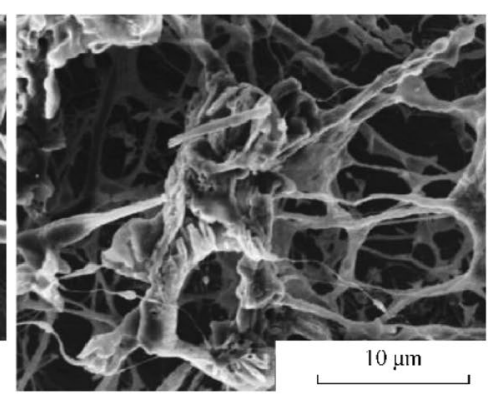

(c) Surface-active Polymer

Fig. 4 SEM pictures of molecule configuration of chemical agents

unit and quaternary ammonium Gemini surfactant unit. Molecular structure diagram of surface-active polymer is shown in Fig. 2, and $\mathrm{R}$ in molecular structure is for $-\mathrm{OR}$, $-\mathrm{NHR},-\mathrm{RSH},-(\mathrm{EO})_{\mathrm{n}}(\mathrm{PO})_{\mathrm{m}} \mathrm{R},-\mathrm{RSO} 3 \mathrm{Na}$ or other functional groups.

Molecular structure and characteristic functional group of surface-active polymer can be characterized by infrared spectrum as shown in Fig. 3.

Surface-active polymer has an amphiphilic structure, as characteristic absorption peak of sulfonate and ether bond appearing in infrared spectrum indicate the presence of hydrophilic group, and characteristic absorption peak of methyl and methylene indicate that there is lipophilic group in molecular structure of surface-active polymer. Characteristic absorption peak of alkene double bond caused by residual monomer shows that polymerization effect occurs in the synthesis process of surface-active polymer.

Results of experiments on physicochemical properties of surface-active polymer in Table 1 show that surface-active polymer has good dissolution performance, the dissolution rate of surface-active polymer is fast at early stage, and then slows down, hydrolysis degree is finally $21.5 \mathrm{~mol} \%$. The viscosity of surface-active polymer can be maintained at a high level, and the viscosity of surface-active polymer is greater than $42.3 \mathrm{mPa} \cdot \mathrm{s}$ after stabilization.

\section{Differences of properties between surface-active polymer and other chemical flooding agents}

Different molecular composition and structure make the properties and characteristics of surface-active polymer

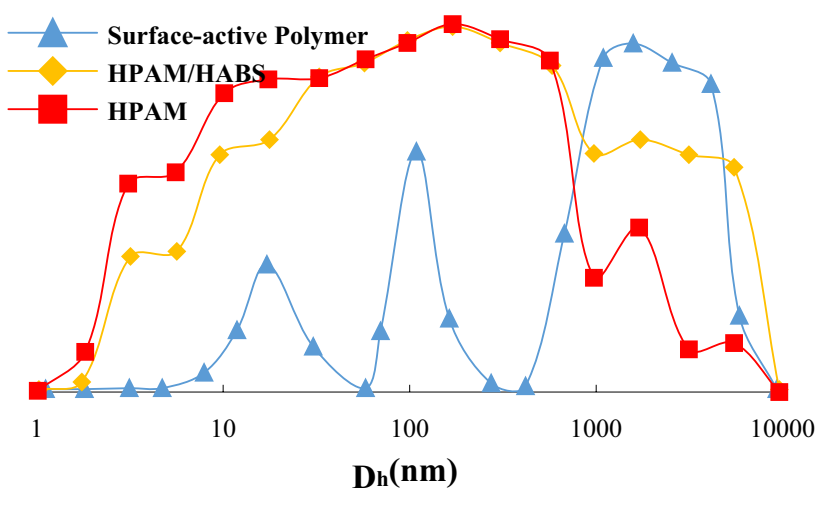

Fig. $5 D_{h}$ distribution curves of chemical agents

very different from those of polymers for chemical flooding. Polymer-surfactant has function and properties both of polymer and surfactant, but there are great differences between surface-active polymer and the binary compound system of polymer and surfactant.

\section{Conformation of molecular aggregation}

SEM pictures of molecule configuration of chemical agents are shown in Fig. 4. Polymer molecules of HPAM present long-chain structures, and long chains entangle each other to form cross-linking structures. Strong electrostatic repulsion causes the molecular chain to stretch to form the backbone and branches of the cross-linking structure. The molecular coil dimension of HPAM/HABS is large and presents network structures. Ion of HABS in binary compound system 


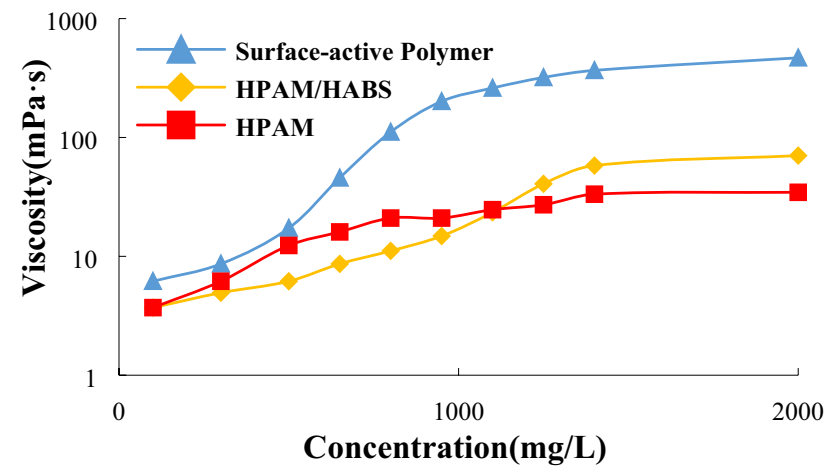

Fig. 6 Viscosity-concentration relationship of chemical agents

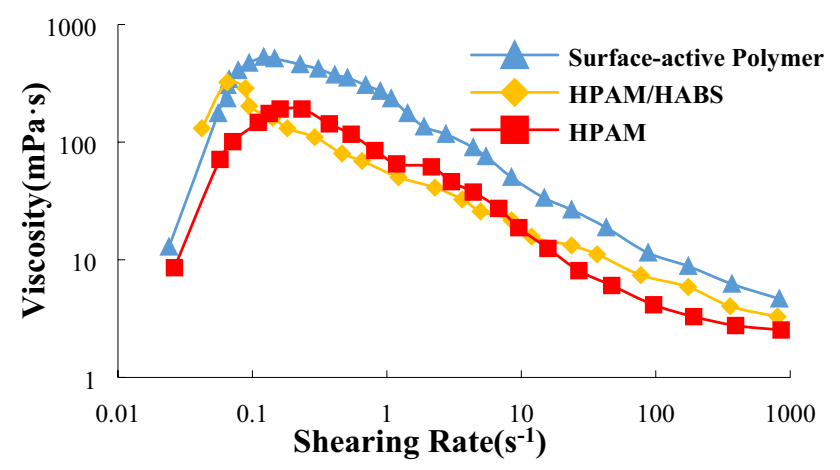

Fig. 7 Relationship between viscosity of chemical agents and shearing rate

compresses polymer molecular string and makes space skeleton sparse. Increased intermolecular thermal motion increases the hydrodynamic diameter. Polymer molecules of surface-active polymer are more stout than HPAM and HPAM/HABS because of the strong association and crosslinking effect between molecules. The molecular string size of surface-active polymer is dispersedly distributed from $1.7 \mu \mathrm{m}$ to $5.7 \mu \mathrm{m}$. The low molecular string size ensures that surface-active polymer is easily accessible to smaller pores.

Surface-active polymer, HPAM and HPAM/HABS at the same mass concentration were tested by dynamic laser scattering apparatus to compare molecular coil dimension. $\mathrm{D}_{\mathrm{h}}$ is used to refer to molecular coil size, as shown in Fig. 5, the $D_{h}$ value of surface-active polymer is the largest, followed by HPAM/HABS, and the $\mathrm{D}_{h}$ value of HPAM is the smallest. The difference between the $D_{h}$ value of HPAM and HPAM/HABS is small, but the $\mathrm{D}_{h}$ value of HPAM and HPAM/HABS is far less than that of surface-active polymer. The distribution of the $\mathrm{D}_{\mathrm{h}}$ value of HPAM is the most concentrated, and the distribution of $\mathrm{D}_{h}$ value of surface-active polymer is the most dispersed.
Table 2 Pressure differences in different parts of the core

\begin{tabular}{llll}
\hline Chemical agents & \multicolumn{2}{l}{$\begin{array}{l}\text { Pressure differences in different parts } \\
(\mathrm{MPa})\end{array}$} \\
\cline { 2 - 4 } & $\begin{array}{l}\text { Front part } \\
\left(\mathrm{P}_{1}-\mathrm{P}_{\text {in }}\right)\end{array}$ & $\begin{array}{l}\text { Central part } \\
\left(\mathrm{P}_{2}-\mathrm{P}_{1}\right)\end{array}$ & $\begin{array}{l}\text { Rear part } \\
\left(\mathrm{P}_{\text {out }}-\mathrm{P}_{2}\right)\end{array}$ \\
\hline Surface-active polymer & 0.361 & 0.038 & 0.001 \\
HPAM/HABS & 0.057 & 0.019 & 0.017 \\
HPAM & 0.033 & 0.021 & 0.015 \\
\hline
\end{tabular}

Table 3 Experimental results of resistance factor and residual resistance factor

\begin{tabular}{lcc}
\hline Chemical agents & Resistance factor & $\begin{array}{l}\text { Residual } \\
\text { resistance } \\
\text { factor }\end{array}$ \\
\hline Surface-active polymer & 303.5 & 117.1 \\
HPAM/HABS & 33.9 & 15.5 \\
HPAM & 20.3 & 6.7 \\
\hline
\end{tabular}

\section{Performance of viscosity}

Surface-active polymer has stronger viscosity increasing effect than HPAM and HPAM/HABS. As shown in Fig. 6, the viscosity of surface-active polymer is the largest, the molecular structure of branch and crosslinking makes the viscosity increase due to introduced functional groups on the polymer molecular chain. The viscosity of HPAM is minimal. Surfactants in binary compound system enable the production of micelles and form complexes of polymer and surfactant. The hydrodynamic volume increases, and the viscosity of HPAM/HABS is slightly greater than the viscosity of HPAM. The viscosity of surface-active polymer, HPAM and HPAM/HABS increase with the increase in concentration, and the amplitude of increase in viscosity of surface-active polymer is the highest.

Relationship between viscosity of chemical agents and shearing rate in Fig. 7 shows that when shearing rate is small, the viscosity of surface-active polymer, HPAM and HPAM/HABS increase with the shearing rate, showing the rheological behavior of shear-thickening. Then the viscosity decreases with the increase in the shearing rate, showing the rheological behavior of shear-thinning. The rheological behavior of shear-thinning and shear-thickening of surfaceactive polymer is more pronounced, as the particle cluster of surface-active polymer is large during shearing process and the network structure of surface-active polymer has poor stability. 


\section{Capability of transmission and flow}

Pressure differences in different parts of the core are shown in Table 2. The pressure differences in different parts of the core after HPAM flooding is small, the transmission capability of HPAM solution is strong, and only a small amount of o HPAM is evenly stranded in the core. The pressure differences in different parts of the core after surface-active polymer flooding is very big, the pressure drop of the first one-third parts is much larger than other parts, and the amount of dynamic retention is the largest, which indicates that the transmission capability of surface-active polymer solution is poor. There is a blockage of the injection surface in the core. The pressure difference in different parts of the core after HPAM/HABS flooding is less than that of surfaceactive polymer flooding and is larger than HPAM flooding, so that the transmission capability of HPAM/HABS solution is between the transmission capability of HPAM solution and surface-active polymer solution.

Experimental results of resistance factor and residual resistance factor of solution of surface-active polymer, HPAM and HPAM/HABS with the same concentration are shown in Table 3. Resistance factor and residual resistance factor of solution of HPAM are both small, because the flexibility of molecular chain in HPAM is strong, and most molecules captured by pore can be dragged out during subsequent water flooding, which leads to the decrease in flow resistance. The resistance factor of surface-active polymer solution is the largest, and the residual resistance factor of surface-active polymer solution is relatively small due to high injection pressure caused by blockage of the injection surface in the core. The flow capability of HPAM/HABS solution is between the flow capability of HPAM solution and surface-active polymer solution.

\section{Positive effects of viscosity and viscoelastic properties to increase displacement efficiency by surface-active polymer flooding.}

Surface-active polymer is a chemical flooding agent that combines the functions of polymer and surfactant, and surface-active polymer solution can achieve the combination of viscosity and activity with low molecular weight and low concentration. Positive effects of viscosity and viscoelastic properties and improvements of interfacial chemical properties are basic characteristics of increasing displacement efficiency by surface-active polymer flooding, and to be further studied on.

Surface-active polymer solution has good performance of increasing viscosity. The interface viscosity of surface-active polymer and oil is much greater than the interface viscosity of water and oil, so the shearing stress of surface-active

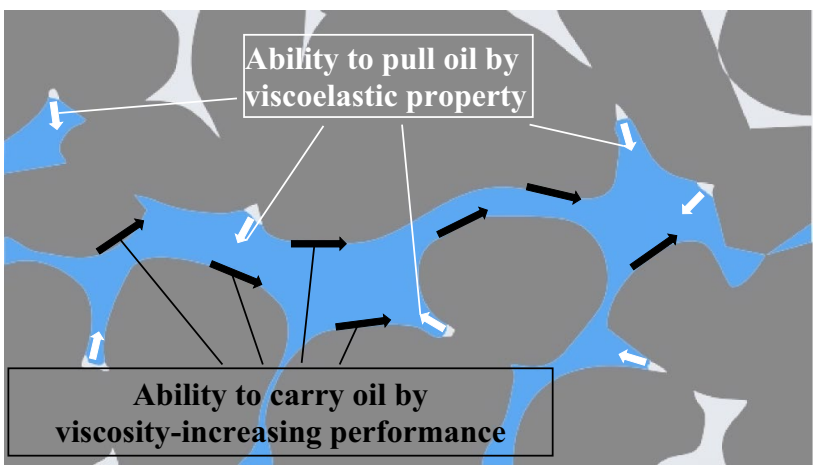

Fig. 8 Positive effects of viscosity and viscoelastic properties

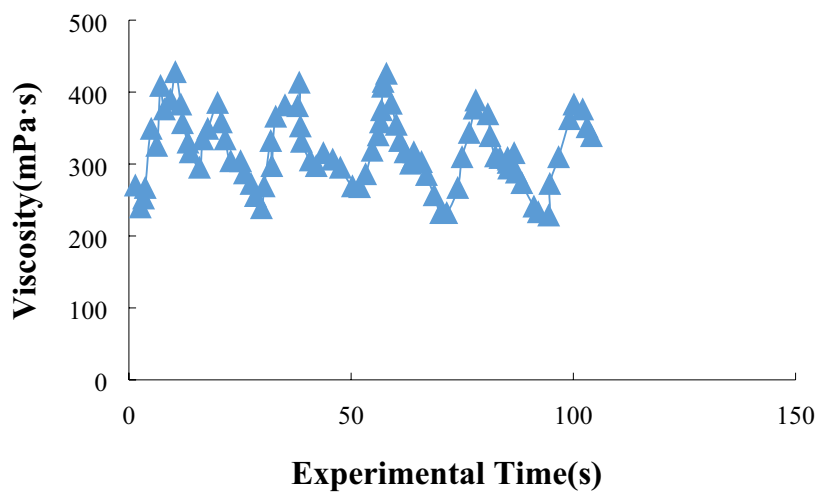

Fig. 9 Dynamic viscosity of surface-active polymer solution

polymer and oil is much greater than the shearing stress of water and oil. Surface-active polymer solution has the ability to carry oil because of the tensile force on oil film produced in the shearing direction (Nilsson et al. 1997; Nedjhioui et al. 2005). Normal stress perpendicular to the displacement direction is produced in the process of viscoelastic surfaceactive polymer solution flowing through porous media, so that surface-active polymer solution has the ability to pull out oil that exists in different directions from the displacement direction (Xia et al. 2006; Hou et al. 2005).

Viscosity-increasing performance makes surface-active polymer have the ability to carry oil, and viscoelastic properties make surface-active polymer have the ability to pull oil, which are shown in Fig. 8. The ability to carry oil and pull oil of surface-active polymer makes residual oil mobilization workable, and this is one of the mechanisms of surface-active polymer flooding for enhancing oil recovery. Therefore, it is necessary to carry out experiments on viscosity-increasing performance and viscoelastic properties of surface-active polymer. 


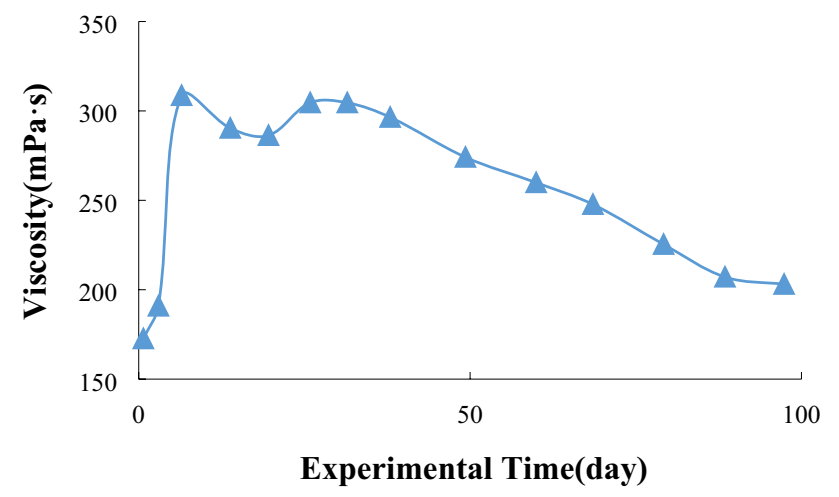

Fig. 10 Viscosity stability curve of surface-active polymer solution

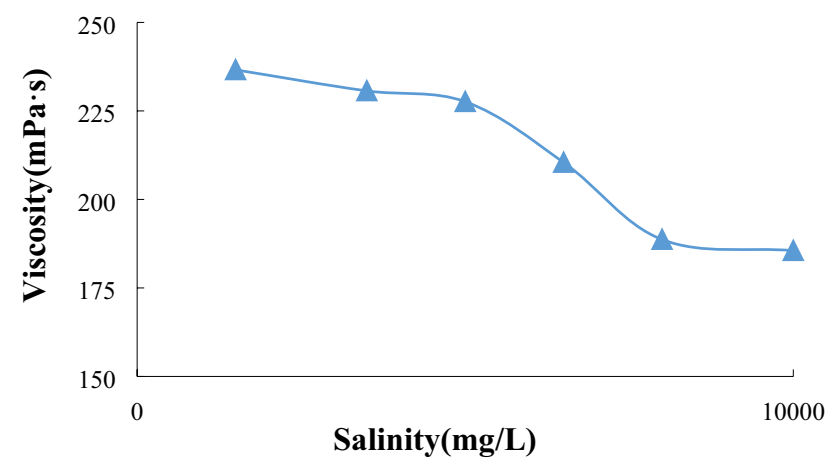

Fig. 11 Relationship between viscosity and salinity of surface-active polymer solution

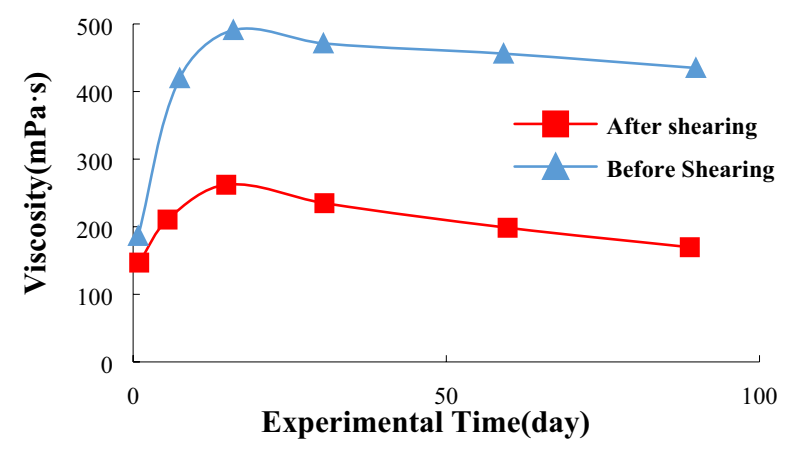

Fig. 12 Viscosity of surface-active polymer solution with time before and after shearing

\section{Viscosity-increasing performance}

Results of viscosity, viscosity stability, shearing resistance and salinity resistance of viscosity experiments show that surface-active polymer solution has good performance of viscosity-increasing and viscosity retention.

The test results in Fig. 9 show that the viscosity-increasing performance of surface-active polymer is strong, and

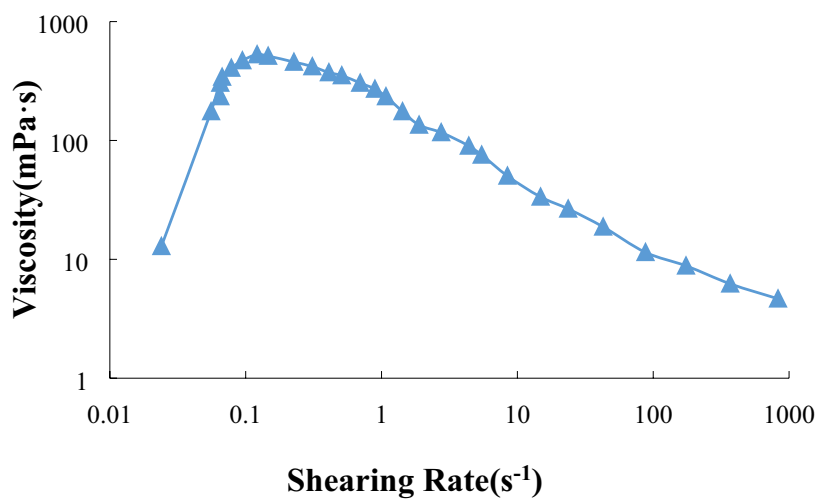

Fig. 13 Viscosity of surface-active polymer solution with shearing rate

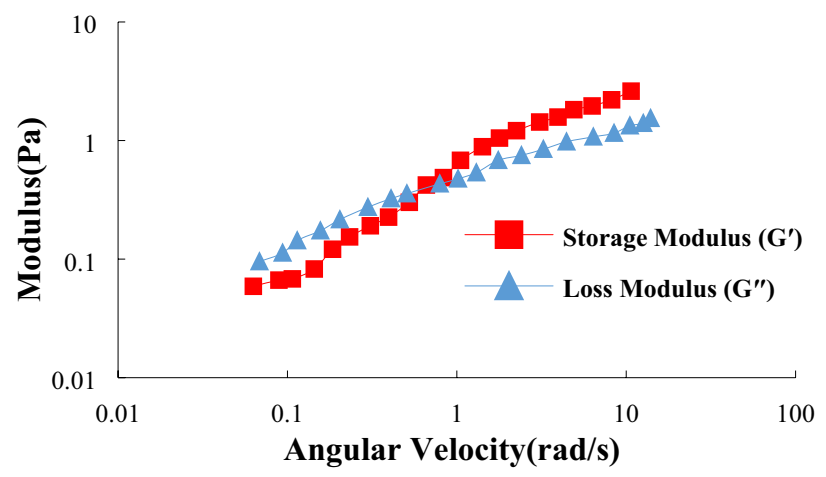

Fig. 14 Modulus of surface-active polymer solution with angular velocity

strong self-crosslinking ability of surface-active polymer makes it easy to form large-size independent molecular aggregation. The apparent viscosity of surface-active polymer solution fluctuates greatly, and the fluctuation of viscosity has regularity.

Surface-active polymer has strong antioxidant ability because of effective decomposition of peroxides by selfoxidation of easily oxidized functional groups in molecular chain of surface-active polymer. Viscosity stability curve of surface-active polymer solution in Fig. 10 shows that the viscosity of surface-active polymer changes little with time, and the retention rate of viscosity is greater than $100 \%$ finally.

Relationship between viscosity and salinity of surfaceactive polymer solution is shown in Fig. 11. The viscosity of surface-active polymer solution decreases when the salinity increases, as the minerals effect on surface-active polymer molecules, the repulsion between molecules decreases, and the molecular chain becomes curly. The retention rate of viscosity of surface-active polymer is relatively high as the salinity increases, and surface-active polymer has good capacity of salt tolerance. 
The viscosity of surface-active polymer solution before and after shearing in 90 days in Fig. 12 shows that the retention rate of viscosity before and after shearing is greater than $100 \%$, so surface-active polymer solution after shearing still has the ability of viscosity restoration.

\section{Viscoelastic properties}

Results of steady-state shearing and dynamic mechanical experiments show that surface-active polymer solution has good performance of viscoelasticity and deformability.

Viscosity of surface-active polymer solution with shearing rate in Fig. 13 shows that surface-active polymer has rheological characteristics of shear-thickening as the viscosity increases when shearing rate is less than $0.1 \mathrm{~s}^{-1}$. The viscosity decreases with the increase in shearing rate when shearing rate is more than $0.1 \mathrm{~s}^{-1}$, so surface-active polymer has rheological characteristics of shear-thinning.

Storage modulus $\left(\mathrm{G}^{\prime}\right)$ and loss modulus $\left(\mathrm{G}^{\prime \prime}\right)$ of surfaceactive polymer increase with the increase in angular velocity in small amplitude oscillatory shear as shown in Fig. 14. $\mathrm{G}^{\prime}$ indicates the storage of energy in the process of fluid deformation, which reflects the elastic properties of the fluid, and $\mathrm{G}^{\prime \prime}$ indicates the consumption of energy in the process of fluid deformation, which reflects the viscous properties of the fluid. $G^{\prime \prime}$ is greater than $G^{\prime}$ when the angular velocity is within a relatively low range, the viscous properties of surface-active polymer solution affect greater than the elastic properties of surface-active polymer solution, and the flow situation of surface-active polymer solution is mainly viscous flow. $G^{\prime}$ is greater than $G^{\prime \prime}$ when the angular velocity is greater than a certain value, the elastic properties of surface-active polymer solution affect greater than the viscous properties of surface-active polymer solution, and the flow situation of surface-active polymer solution is mainly elastic flow.

The first normal stress difference is one of the most significant features of viscoelastic fluid, and the change of first

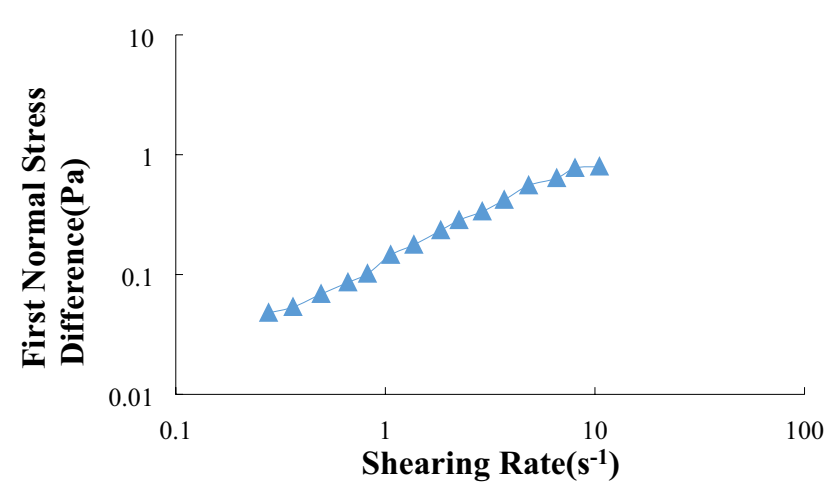

Fig. 15 First normal stress difference of surface-active polymer solution with shearing rate normal stress difference with shearing rate reflect the elasticity of fluid. The first normal stress difference of surfaceactive polymer solution tends to rise with shearing rate as shown in Fig. 15.

\section{Improvements of interfacial chemical properties to increase displacement efficiency by surface-active polymer flooding.}

The interfacial chemical properties in the displacement process refer to the physicochemical characteristics of the interface system of displacing phase and displaced phase, and the change of interfacial chemical properties affects the physical and chemical law and processes in the displacement process. Surface-active polymer can improve the interfacial chemical properties of oil and water and then improve microscopic displacement efficiency.

\section{Reduction of interfacial tension}

Different polar groups in surface-active polymer solution tend to dissolve in similar polar solutions, so that polar difference on the oil-water interface decreases, the

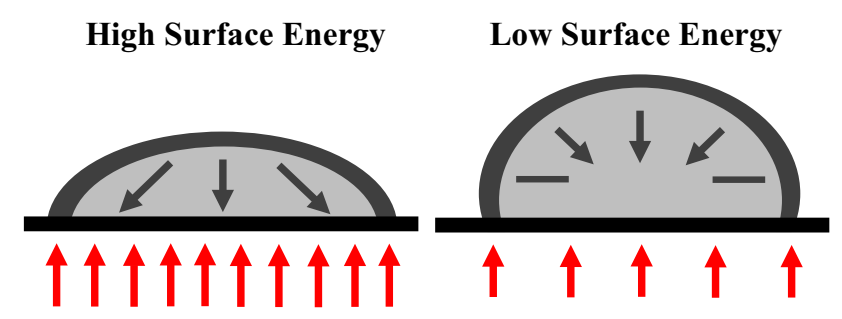

Fig. 16 Comparison of surface energy

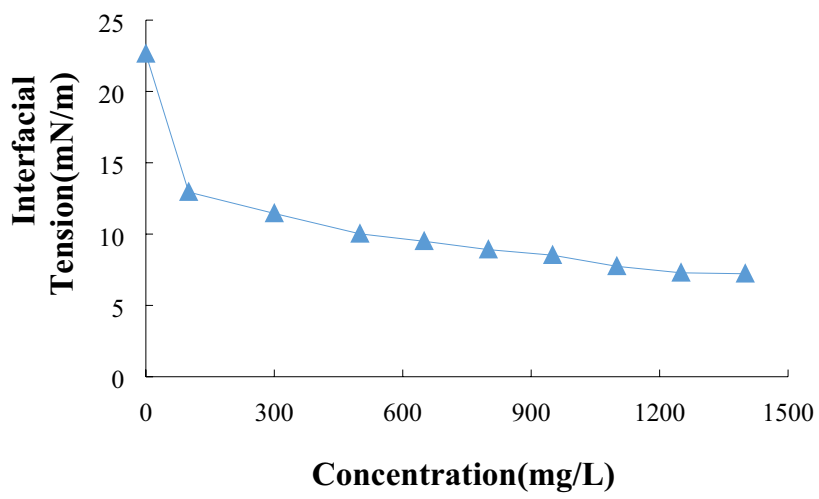

Fig. 17 Interfacial tension of surface-active polymer with different concentrations 


\section{Surfactant Group in \\ Surface-active Polymer}

Hydrophilic Group

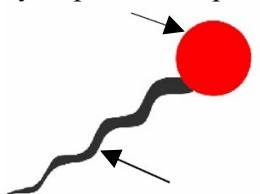

Lipophilic Group
Schematic Diagram of Emulsification and Solubility

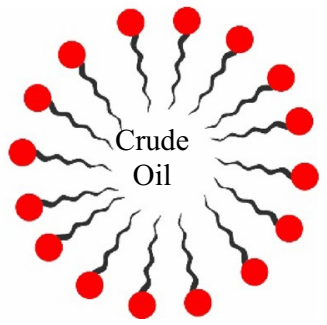

Fig. 18 Schematic diagram of emulsification and solubility performance of surface-active polymer

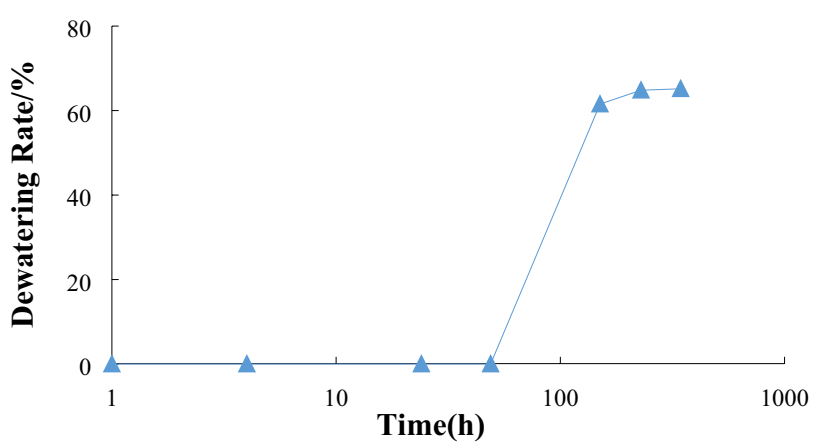

Fig. 19 Dewatering rate of emulsion generated by surface-active polymer with time

interfacial tension decreases, and oil adsorbed on the rock surface dissolves in the displacing phase, thus improving microscopic displacement efficiency (Shah 1981), Touhami et al. (2001). Comparison of surface energy is shown in Fig. 16.

The results of interfacial tension test of surface-active polymer with different concentration in Fig. 17 show that surface-active polymer can reduce the interfacial tension by a small extent. With the increase in the concentration of surface-active polymer, the interfacial tension reduces rapidly first and then changes little. However, even surface-active polymer with high concentration is difficult to achieve ultra-low interfacial tension.

\section{Emulsification of crude oil}

The emulsification performance is an important property of surface-active polymer to improve microscopic displacement efficiency, especially in displacement mode of non-ultralow interfacial tension system. In the past, ultra-low interfacial tension was pursued to improve displacement efficiency in most of the chemical flooding, and the emulsification of crude oil by chemical agents was not paid enough attention.

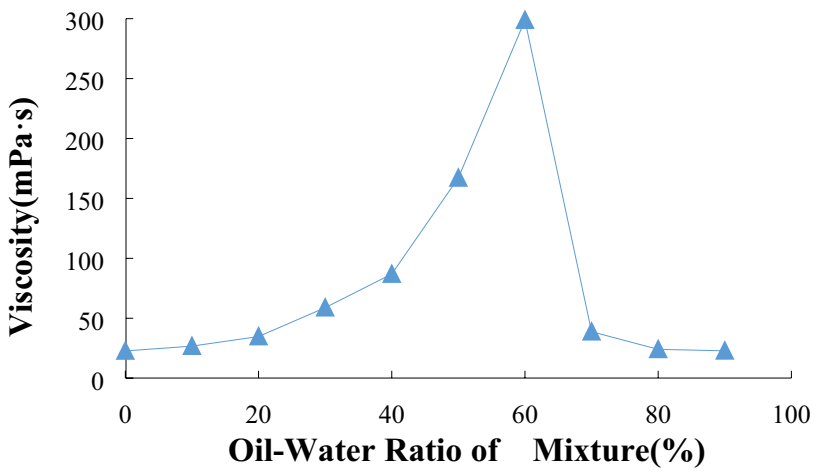

Fig. 20 Viscosity of different oil-water ratio mixture

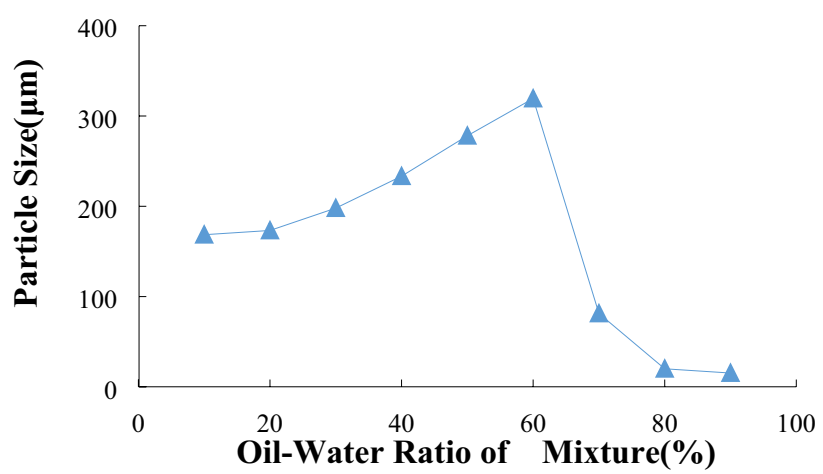

Fig. 21 Particle size of emulsion droplet of different oil-water ratio mixture

Surface-active polymer molecules are directed to adsorption at the oil-water interface in the process of surface-active polymer flooding, reduced interfacial tension makes crude oil more dispersed in water, and residual oil forms stable oilin-water emulsion. Surface-active polymer changes the properties of original interfacial film of oil and water and forms a new interfacial film of oil and surface-active polymer in the process of emulsification. The increase in elasticity of the interfacial film and the decrease in adhesion of residual oil on pore walls are beneficial to the deformation, shedding and emulsification of residual oil (Wang et al. 1999; Kang et al. 2011). Schematic diagram of emulsification and solubility performance of surface-active polymer is shown in Fig. 18. The emulsion has certain stability as the interface film reduces the possibility of re-adhesion. Therefore, surface-active polymer with the ability of solubilizing and emulsifying crude oil can improve microscopic displacement efficiency.

The smaller dewatering rate is, the higher the stability of the emulsion is, and the stronger the ability of emulsifying crude oil is. The test results in Fig. 19 show that there is no water separating from the emulsion in $24 \mathrm{~h}$, and the dewatering time is about $48 \mathrm{~h}$. The emulsification state can

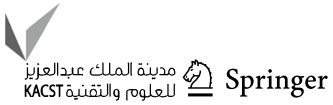




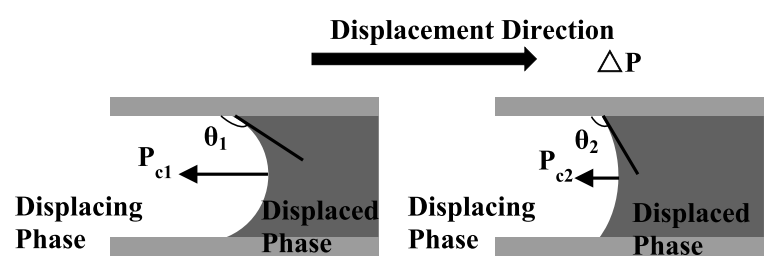

Fig. 22 Schematic diagram of trend to water wettability

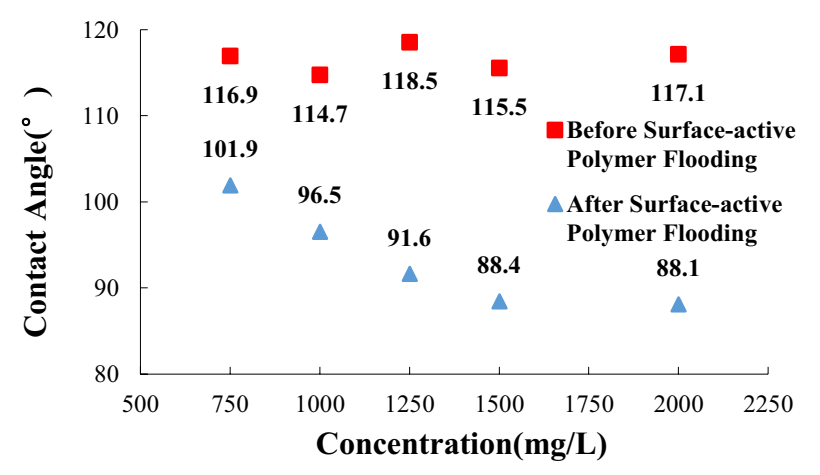

Fig. 23 Contact angle before and after surface-active polymer flooding with different concentration

be maintained after 7 days of stability, and the maximum dewatering rate is $63 \%$, which shows surface-active polymer solution has strong ability of emulsifying crude oil.

The viscosity of the mixture of surface-active polymer and crude oil configured according to different proportions was determined, and the viscosity of the mixture varies greatly as viscosity of different oil-water ratio mixture shown in Fig. 20. The viscosity of the mixture mutates when moisture content increases to $60 \%$, and the relative motion between dispersed droplets and the surface energy of interphase leads to the rapid increase in viscosity. According to the theory of viscosity mutation, the mutation point of viscosity is the transition point of emulsion type. The mixture is W/O type emulsion when moisture content is less than $60 \%$, and the mixture changes to $\mathrm{O} / \mathrm{W}$ type emulsion as the moisture content is greater than $60 \%$. The average viscosity of formed $\mathrm{O} / \mathrm{W}$ type emulsion is less than that of W/O type emulsion.

Using electron microscope to observe the microscopic morphology of emulsion and to compare the average diameter of emulsion droplets. The average diameter of O/W type emulsion droplets is significantly lower than that of W/O type emulsion droplets as shown in Fig. 21.

\section{Trend to water wettability}

Trending to water wettability play a positive role for surfaceactive polymer flooding to improve microscopic displacement efficiency, especially in displacement mode of nonultralow interfacial tension system.

Wettability is a comprehensive characteristic of reservoir rock, the change of wettability will affect capillary pressure and relative permeability, and then affect microscopic displacement efficiency. Functional groups such as alkyl sulfonate surfactant unit and quaternary ammonium Gemini surfactant unit on the molecular chain, surface-active polymer is adsorbed on the surface of reservoir rock, hydrophobic reservoir rock trend to water wettability, and schematic diagram of trend to water wettability by surface-active polymer flooding is shown in Fig. 22. The direction of capillary pressure turns to displacement direction, and displacement resistance decreases. The contact angle between crude oil and reservoir rock surface decreases, the adhesion of reservoir rock to crude oil decreases, and the change of relative permeability is beneficial to oil flow, thus improving microscopic displacement efficiency (Morrow et al. 1986, Mohan et al. 2011).

The results of experiments on before and after surface-active polymer flooding with different concentration in Fig. 23 show that the contact angle of reservoir rock decreases after surface-active polymer flooding, and the performance of trending to water wettability of surface-active polymer flooding is obvious. The reduction amplitude of contact angle increases with the increase in concentration of surface-active polymer, the contact angle is less than $90^{\circ}$ when the concentration of surface-active polymer is greater than 1500 , at which point, the surface-active polymer shows the performance of wettability reversal.

\section{Conclusions}

Surface-active polymer is a novel active multifunctional polymer, and specific multiple functional groups such as sulfonate, ether bond, methyl, methylene and alkene on molecular chain makes surface-active polymer have both viscosity-increasing ability and surface activity. Surfaceactive polymer has good dissolution performance, viscosity of surface-active polymer can be maintained at a high level, and the viscosity of surface-active polymer is greater than $42.3 \mathrm{mPa} \cdot \mathrm{s}$ after stabilization.

The molecular aggregation conformation, viscosity performance and flow capacity of surface-active polymer are significantly different from those of common polymer and binary compound system of polymer and surfactant. Polymer molecules of surface-active polymer are more stout than HPAM and HPAM/HABS, and molecular string size of 
surface-active polymer is lower to ensure that surface-active polymer is easier accessible to smaller pores. Surface-active polymer has stronger viscosity increasing effect than HPAM and HPAM/HABS. The resistance factor of surface-active polymer solution is the largest, and the residual resistance factor of surface-active polymer solution is relatively small.

Surface-active polymer solution has good performance of viscosity-increasing and viscosity retention. Strong selfcrosslinking ability of surface-active polymer makes the viscosity-increasing performance of surface-active polymer strong. The apparent viscosity of surface-active polymer solution fluctuates greatly, and the fluctuation of viscosity has regularity. The viscosity of surface-active polymer changes little with time, and the retention rate of viscosity is greater than $100 \%$ after 100 days. Surface-active polymer has good capacity of salt tolerance, and surface-active polymer solution after shearing still has the ability of viscosity restoration. Surface-active polymer solution has good performance of viscoelasticity and deformability. Surface-active polymer has rheological characteristics of shear-thickening and shear-thinning. Storage modulus $\left(\mathrm{G}^{\prime}\right)$ and loss modulus $\left(G^{\prime \prime}\right)$ of surface-active polymer increase with the increase in angular velocity in small amplitude oscillatory shear, and the first normal stress difference of surface-active polymer solution tends to rise with shearing rate.

With the increase in the concentration of surface-active polymer, the interfacial tension reduces. Surface-active polymer changes the properties of original interfacial film of oil and water and forms a new interfacial film of oil and surface-active polymer in the process of emulsification. The emulsion has certain stability as the interface film reduces the possibility of re-adhesion. The contact angle of reservoir rock decreases after surface-active polymer flooding, the performance of trending to water wettability of surfaceactive polymer flooding is obvious, and surface-active polymer shows the performance of wettability reversal. So surface-active polymer can reduce the interfacial tension, and the emulsification performance and trending to water wettability are important for surface-active polymer flooding to improve microscopic displacement efficiency, especially in displacement mode of non-ultralow interfacial tension system.

In general, positive effects of viscosity and viscoelastic properties and improvements of interfacial chemical properties are basic characteristics of increasing displacement efficiency by surface-active polymer flooding.

Funding This project has been carried out under the framework of Major Projects of National Science and Technology (No.2016ZX05010002-004 and 2016ZX05023005-001-003), and the study was financially supported by China Postdoctoral Science Foundation (No. 2019M651255), HeiLongJiang Postdoctoral Foundation
(No. LBH-Z18039) and National Natural Science Foundation of China (No. 51804078).

Open Access This article is licensed under a Creative Commons Attribution 4.0 International License, which permits use, sharing, adaptation, distribution and reproduction in any medium or format, as long as you give appropriate credit to the original author(s) and the source, provide a link to the Creative Commons licence, and indicate if changes were made. The images or other third party material in this article are included in the article's Creative Commons licence, unless indicated otherwise in a credit line to the material. If material is not included in the article's Creative Commons licence and your intended use is not permitted by statutory regulation or exceeds the permitted use, you will need to obtain permission directly from the copyright holder. To view a copy of this licence, visit http://creativecommons.org/licenses/by/4.0/.

\section{References}

Gurgel A, Moura MCPA, Dantas TNC et al (2008) A review on chemical flooding methods applied in enhanced oil recovery. Braz J Petrol Gas 2(2)

Liao G, Wang Q, Wang H et al (2017) Chemical flooding development status and prospect. Acta Petrolei Sinica 38(02):196-207

Stavland A, Jonsbraten H, Lohne A, et al. (2010) Polymer floodingflow properties in porous media versus rheological parameters. In SPE EUROPEC/EAGE annual conference and exhibition. society of petroleum engineers.

Xia H, Wang G, Ma W et al (2008) Influence of viscoelasticity and interfacial tension of non-alkali binary compound solution on recovery efficiency of residual oil after water flooding. Acta Petrolei Sinica 29(1):106-110

Yu Q, Liu Y, Liu X et al (2018) Experimental study on seepage flow patterns in heterogeneous low-permeability reservoirs. J Petrol Explor ProducTechnol 8(2):589-596

Yu Q, Jiang H, Song Y et al (2012) Chemical flooding for enhanced recovery. Energy Sour Part A Recov Util Environ Effects 34(5):478-483

Sun L, Wu X, Zhou W et al (2018) Technologies of enhancing oil recovery by chemical flooding in Daqing Oilfield. NE China Petrol Explor Develop 45(04):636-645

Liu P, Zhang S, Yang N et al (2012) A novel surface active polymer oil displacement agent. Petrol Explor Develop 39(5):619-623

Shi L. (2008) Study on performance evaluation and Mechanism of polymer surfactants. In Doctoral dissertation, Institute of Porous Flow and Fluid Mechanics of GUCAS.

Nilsson S, Lohne A, Veggeland K (1997) Effect of polymer on surfactant flooding of oil reservoirs. Colloids Surf A 127(1-3):241-247

Nedjhioui M, Moulai-Mostefa N, Morsli A et al (2005) Combined effects of polymer/surfactant/oil/alkali on physical chemical properties. Desalination 185(1-3):543-550

Xia H, Wang D, Wang G et al (2006) Elastic behavior of polymer solution to residual oil at dead-end. Acta Petrolei Sinica 27(02):72-76

Hou J, Liu Z, Zhang S et al (2005) The role of viscoelasticity of alkali/ surfactant/polymer solutions in enhanced oil recovery. J Petrol Sci Eng 47(3-4):219-235

Shah DO (ed) (1981) Surface phenomena in enhanced oil recovery. Plenum Press, New York, pp 39-43

Touhami Y, Rana D, Neale GH et al (2001) Study of polymer-surfactant interactions via surface tension measurements. Colloid Polym Sci 279(3):297-300 
Wang X, Li Z, Qian Y et al (1999) An Investigation of Coalescence of Emulsified Droplets in System Crude Oil/ Asp Flooding Solution. Oilfield Chem 16(04):352-355

Kang W, Xu B, Wang Y et al (2011) Stability mechanism of W/O crude oil emulsion stabilized by polymer and surfactant. Colloids Surf A 384(1-3):555-560

Morrow NR, Lim HT, Ward JS (1986) Effect of crude-oil-induced wettability changes on oil recovery. SPE Form Eval 1(01):89-103
Mohan K, Gupta R, Mohanty KK (2011) Wettability altering secondary oil recovery in carbonate rocks. Energy Fuels 25(9):3966-3973

Publisher's Note Springer Nature remains neutral with regard to jurisdictional claims in published maps and institutional affiliations. 